\title{
Detection of Antifungal Activity of Cinnamon Extract on Candida Species Isolated from Diabetic Patients with Urinary Tract Infection Pre-COVID-19 Era
}

\author{
Waleed O.A. KaramAlla ${ }^{1}$, Hadia Abass Eltaib ${ }^{1}$, Ghanem M. Mahjaf ${ }^{1}$ and Mosab Nouraldein Mohammed \\ Hamad $^{2 *}$ \\ ${ }^{1}$ Department of Medical Microbiology, Faculty of Medical Laboratory Sciences, Shendi University, Sudan \\ ${ }^{2}$ Head of Parasitology Department, College of Health and Allied Sciences, St. Joseph University In Tanzania, Dar Es Salaam, \\ Tanzania
}

*Corresponding Author: Mosab Nouraldein Mohammed Hamad

Head of Parasitology Department, College of Health and Allied Sciences, St. Joseph University In Tanzania, Dar Es

Salaam, Tanzania

Article History: | Received: 17.01.2022 | Accepted: 22.02.2022 | Published: 27.02.2022 |

\begin{abstract}
This study aimed to evaluate the antifungal activity of Cinnamon extract on Candida species isolated from 100 diabetic patients suffering from urinary tract infection between May to August 2018. Twenty-five Candida species were isolated, different Candida species were isolated then identified biochemically, in vitro sensitivity testing using well diffusion technique against Cinnamon extract was done. The cinnamon extract showed good antifungal activity against Candida species. The largest zone of inhibition against Candida tropicalis was (25 mm) and the least zone of inhibition was against Candida kefyr was $(10 \mathrm{~mm})$. The results of antimicrobial activity of crude extract were compared with the positive control (Clotrimazole) for evaluating their relative percentage inhibition and statistical significance the aqueous extract exhibited maximum relative percentage inhibition against Candida kefyr (89\%) and minimum relative percentage inhibition against Candida glabrata was (12.3\%). The $p$. values $(0.018)$ are statistically significant.

Keywords: Candida spp, Cinnamon, Shendi, Antifungal activity, Diabetic, UTI.

Copyright (C) 2022 The Author(s): This is an open-access article distributed under the terms of the Creative Commons Attribution 4.0 International License (CC BY-NC 4.0) which permits unrestricted use, distribution, and reproduction in any medium for non-commercial use provided the original author and source are credited.
\end{abstract}

\section{INTRODUCTION}

Since time immemorial, mankind has searched for medications to remove pain and cure various diseases. Evidence exists for the use of medicinal plants up to 60,000 years ago but additional newly, a 5000year-old Sumerian clay slab was discovered verifying the utilization of medicinal plants for the preparation of drugs. Nowadays it has been estimated that more than $50 \%$ of available drugs have originated in some way from plants [1]. These compounded drugs comprised medicinal plants along with drugs of animal and plant origin. If the drug was prepared from several medicinal plants, minerals, and rare animals, it was highly valued and sold at a premium [1]. Many medicinal plants are employed as self-medication or are used upon the suggestion of a physician or pharmacist. They are employed both independently and/or in combination as complementary therapies to synthetic drugs. It is imperative for an adequate and successfully applied therapy that an accurate early diagnosis is made of the illness along with a selection of the appropriate pharmacological effects associated with the specific herbal components [1].

Community-acquired Urinary Tract Infections (UTIs) are a frequent problem worldwide that is caused by microbial invasion to different tissues of the urinary tract. Fungi are a part of the microbial inhabitants that may contribute as fungal uropathogens in UTIs. In the last 2.5 decades, the fungal UTIs due to Candida genus yeast have increased significantly [2]. The predisposing factors of UTIs include gender, genetic predisposition, behavioral factors, urologic structural abnormalities, diabetes, immunosuppression, pregnancy, hypertension,

Citation: Waleed O.A. KaramAlla, Hadia Abass Eltaib, Ghanem M. Mahjaf and Mosab Nouraldein Mohammed Hamad (2022). Detection of Antifungal Activity of Cinnamon Extract on Candida Species Isolated from Diabetic Patients with Urinary Tract Infection Pre-COVID-19 Era. SAR J Pathol Microbiol, 3(1), 5-9. 
stone formation, nosocomially acquired infections, and instrumentation like catheterization [3]. The healthy urinary tract is sterile so, the presence of Candida yeasts in the urine implicates a variety of clinical situations Candiduria can be demonstrated as symptomatic or asymptomatic UTIs; the incidence of more subordinate urinary tract infections induced by yeasts is fourfold more expected in females than in males. Furthermore, the results of different studies have indicated that UTIs in women are very common [3].

Lower UTI with Candida usually happens in patients with urinary catheters, generally after antibiotic treatment, although candidal and bacterial infections regularly happen simultaneously. C. albicans prostatitis happen infrequently in patients with diabetes, usually after instrumentation. Renal candidiasis is usually spread hematogenously and commonly originates from the GI tract. Ascending infection is likely and occurs mainly in patients with nephrostomy tubes, another permanent indwelling instrument, and stents. At high risk are patients with diabetes and those who are immunocompromised because of a tumor, AIDS, chemotherapy, or immunosuppressants. The main original of candidemia in such high-risk hospitalized patients is an indwelling intravascular catheter. kidney transplantation raise the risk to of the combination of indwelling catheters, stents, antibiotics, anastomotic leaks, obstruction, and immunosuppressive therapy [4]. The consumption of cinnamon and its usage for a variety of other purposes has a long history. Even Moses used cinnamon in his holy oil in the Bible's Old Testament. The spice business of historic Europe thrived on cinnamon as one of its primary luxury interests. Cinnamon is now grown in many regions of the world and has been used medicinally for some time. With the advent of modern technology; scientists have even proved that cinnamon is a viable treatment for some bacterial and fungal infections. Getting rid of yeast diseases is one medicinal use cinnamon offers remarkable efficacy in. You likely have some cinnamon bark powder already in your house; you can add it to your yeast infection treatment to bolster the power of your current therapy [5]

\section{MATERIAL AND METHODS \\ Study design}

A cross-sectional, Hospital based study.

\section{Study period}

From May 2018 to August 2018

\section{Study population}

Diabetic patients in Shendi hospitals- Sudan

\section{Sample size}

Hundred urine sample from diabetic patients

\section{Ethical considerations}

The study was reviewed and approved by the s cientific and the ethical committee of Shendi University

\section{Data collection}

Data was collected by using questionnaire.

\section{Study setting}

Shendi locality, River Nile State, Sudan. Shen di is a town in northern of Sudan beside the River Nile a nd Almatamah town also far $150 \mathrm{~km}$ northeast from $\mathrm{Kh}$ artoum the capital of Sudan $\left(16^{\circ} 41^{\prime} \mathrm{N} 33^{\circ} 25^{\prime} \mathrm{E}\right)$. The are $\mathrm{a}$ is inhabited by the Ga'aleen Tribe.

\section{Method}

\section{Specimen collection}

After take consent, patients at risk to become infected with fungal infection sample well be collected by standard procedure (Midstream urine MSU) by giving the patient a sterile, dry, wide-naked, leak-proof container and explain the importance of collecting a specimen with as little contamination as possible and cultured in S.D A media (Sabrouds Dextrose Agar), then incubated for $24 \mathrm{~h}$. If the culture shows significant growth, doing gram stain, biochemical tests to identify the causative agent then susceptibility testing to cinnamon extract will be done.

\section{Culture of urine specimen}

Urine sample were mixed well by rotating urine container several times. Beside opened Bunsen burner urine container was opened and Nichrome loop was inserted after sterilization by flaming and cooling. Small amount of urine sample was taken by loop and inoculated by making firstly well in Sabrauds dextrose agar media then making primary lines from the well then secondary lines from primary lines then tertiary lines from secondary lines finally zigzag from last line of tertiary lines. 4-The inoculated plates were incubated in incubator at $37^{\circ} \mathrm{C}$ for $24 \mathrm{~h}$ under aerobic condition.

Interpretation of culture growth

The plates were examined for any significant yeast growth. The isolated yeast was then identified by colonial morphology, Gram stain and biochemical tests.

\section{Preparation of plant extract}

The plant sample was coarsely powdered using mortar and pestle. Coarsely sample was successively extracted with petroleum ether using soxhelt extractor apparatus. Extraction carried out for about five hours till the color of solvents at the last siphoning time returned colorless. Solvents were evaporated under reduced pressure using rotary evaporator apparatus. Finally, extracts allowed to air in Glass container till complete dryness and the yield

\section{Procedure of inoculation in Mueller Hinton agar plates and applying cinnamon extract}

By the loop the tops of each of 3-5 colonies were touched, of similar appearance, of the organism to 
be tested. The growth was transferred to a tube of sterile saline and mixed then compared the tube with the turbidity standard and adjusted the density of the test suspension to that of the standard by adding more bacteria or more sterile saline. The plates were inoculated by dipping a sterile swab into the 27 inoculums. The excess 27 inoculums was removed by pressing and rotating the swab firmly against the side of the tube above the level of the liquid. The swab was streaked all over the surface of the medium three times, rotating the plate through an angle of $60^{\circ}$ after each application. Finally, the swab was passed round the edge of the agar surface. The inoculums were left to dry for a few minutes at room temperature with the lid closed. By using glass poorer of size $6 \mathrm{~mm}$ in diameter, 5 pores were made in agar plate then the pores were filled by cinnamon extract by using automatic pipette in volume $50 \mu .1$ of concentrations $1,0.5,0.25$, $0.15 \mathrm{~g} / 100 \mathrm{ml}$. The plates were incubated for $24 \mathrm{~h}$ in incubator under aerobic condition in $37^{\circ} \mathrm{C}$.

\section{Interpreting the sensitivity of cinnamon extract}

The diameter of each zone (including the diameter of the disc) had been measured and recorded in $\mathrm{mm}$. The measurements were made with a ruler on the under-surface of the plate without opening the lid.

\section{DATA ANALYSIS}

Data was analyzed by using online web site htt ps//www.graphpad.comto determine the mean and stand ard deviation of the data.Proportional data were present ed as frequencies and percentages.

\section{RESULT}

A total of one hundred patients with UTI patients were enrolled in this study. The mean age was $(56.34 \pm 6.7)$ years (Table 1). Male frequency is $(24 \%)$ and female frequency is $(76 \%)$. The main causative agent of UTI caused by Candida species in the study population was Candida glabratan=7(33.4\%), Candida tropicalisn=4 (19\%), Candida Albicans $\mathrm{n}=4(19 \%)$ and Candida kefyr $\mathrm{n}=3(14.3 \%)$ Candidakrussein=3(14.3\%) (Table2).Antimicrobial susceptibility of cinnamon extract has the largest zone of inhibition against Candida tropicalis was $(25 \mathrm{~mm})$ and the least zone of inhibition against Candida kefyr was $(10 \mathrm{~mm})$ (Table 4). The results of antimicrobial activity of the crude extract were compared with the positive control (Clotrimazole) for evaluating their relative percentage inhibition, the aqueous extract exhibited maximum relative percentage inhibition against Candida kefyr (89\%) and minimum relative percentage inhibition against Candida glabrata was (12.3\%) (Table 3\& 4). Antibacterial activities of extracts were checked by well diffusion method. The concentrations ofaqueous extract used was $1,0.5,0.25$ and $0.125 \mathrm{~g} / 100 \mathrm{ml}$.MIC values of aqueous extracts of cinnamon on test organisms which the lowest concentration of cinnamon aqueous extract able to inhibit the growth of Candida was $(0.187 \mathrm{~g} / 100 \mathrm{ml})$ appear against Candida krussei followed by Candida kefyr $(0.208 \mathrm{~g} / 100 \mathrm{ml})$, Candida tropicalis $\quad(0.343 \mathrm{~g} / 100 \mathrm{ml}), \quad$ Candida albican $(0.375 \mathrm{~g} / 100 \mathrm{ml})$ and Candida glabrata $(0.458 \mathrm{~g} / 100 \mathrm{ml})$ (Table 5).

Table-1: Shows population distribution according to ages and gender

\begin{tabular}{|l|l|l|l|l|}
\hline Age group & Number & Male & Female & \% \\
\hline Lessthan40 & 14 & 3 & 11 & $14 \%$ \\
\hline $41-50$ & 16 & 2 & 14 & $16 \%$ \\
\hline $51-60$ & 31 & 12 & 19 & $31 \%$ \\
\hline More than 60 & 39 & 7 & 32 & $39 \%$ \\
\hline Total & $\mathbf{1 0 0}$ & $\mathbf{2 4}$ & $\mathbf{7 6}$ & $\mathbf{1 0 0 \%}$ \\
\hline
\end{tabular}

Age $($ mean \pm SD $)=(56.34 \pm 6.7)$

Table-2: Shows percentage of Candida isolated from the urine.

\begin{tabular}{|l|l|l|}
\hline Candia species & Number & $\%$ \\
\hline Candida glabrata & 7 & $33.4 \%$ \\
\hline Candida albican & 4 & $19 \%$ \\
\hline Candida tropicalis & 4 & $19 \%$ \\
\hline Candida kefyr & 3 & $14.3 \%$ \\
\hline Candida krussei & 3 & $14.3 \%$ \\
\hline Total & 21 & 100 \\
\hline
\end{tabular}

Table-3: Shows Mean inhibition zone of Cinnamon and Clotrimazole

\begin{tabular}{|l|l|l|}
\hline Type of tea used & Number & P-value \\
\hline Clotrimazole & $21.16 \pm 6.7$ & \multirow{2}{*}{0} \\
\hline Cinnamon & $11.23 \pm 2.66$ & 0.018 \\
\hline
\end{tabular}


Table-4: Shows Relative percentage inhibitions of Cinnamon extract compared to Clotrimazole

\begin{tabular}{|l|l|}
\hline Test organisms & Relative percentage inhibition (\%) \\
\hline Candida glabrata & $12.3 \%$ \\
\hline Candida albican & $24 \%$ \\
\hline Candida tropicalis & $25.9 \%$ \\
\hline Candida kefyr & $89 \%$ \\
\hline Candida krussei & $35 \%$ \\
\hline
\end{tabular}

Table-5: Shows Antimicrobial susceptibility of cinnamon extract compared to Clotrimazole

\begin{tabular}{|l|l|l|l|}
\hline \multirow{2}{*}{ Candida species } & \multicolumn{2}{|l|}{ Inhibition zone diameter $(\mathbf{m m})$} & \\
\cline { 2 - 4 } & $\begin{array}{l}\text { Cinnamon extract } \\
(\mathbf{1} \text { g/100ml })\end{array}$ & $\begin{array}{l}\text { Positive control } \\
\text { Clotrimazole } \\
\mathbf{( 1 ~ g / 1 0 0 m l )}\end{array}$ & $\begin{array}{l}\text { MIC } \\
\text { g/100ml }\end{array}$ \\
\hline Candida glabrata & 7.4 & 21.4 & 0.458 \\
\hline Candida albican & 12.25 & 25 & 0.375 \\
\hline Candida tropicalis & 14.5 & 28.5 & 0.343 \\
\hline Candida kefyr & 10 & 10.6 & 0.208 \\
\hline Candida krussei & 12 & 20.3 & 0.187 \\
\hline
\end{tabular}

\section{DISCUSSION}

Twenty-one out of hundred patients $(21 \%)$ were positive for Candiduria, the recovery rate of Candida species from urine samples varies in different studies. In the present study, in a study conducted by Nademi et al., nosocomial candiduria was reported in $4.3 \%$ (5 out of 115) of hospitalized patients. Furthermore, Yismaw et al. reported significant candiduria in $7.5 \%$ and $17.1 \%$ of asymptomatic and symptomatic patients with diabetes, respectively. The overall candiduria rate was $8.3 \%$ (35 out of 422). Likewise, Goyal et al., Zarei et al., and Padawer et al. reported candiduria in $2.36 \%, 16.5 \%$, and $19.49 \%$ of their study populations, respectively. In a comparative study by da Silva Krenke et al., candiduria was reported in $30 \%$ and $16 \%$ of diabetic and non-diabetic patients, respectively. The disagreements between the outcomes of different studies may be due to differences in analysis populations, underlying factors, preventative measures of patients and hospitals, and geographical area. Although C. albicans is reported as the major Candida species causing candiduria in some studies, an increasing trend in the prevalence of candiduria due to non-albicans Candida species was shown by some researchers. The study found that $\mathrm{C}$. glabrata was the most isolated species $(33.4 \%)$ followed by C. albicans (19\%), C. tropicalis(19\%), C. krussei(14.3\%), and C. kefyr $(14.3 \%)$, the higher incidence of non-albicans Candida species, including C. glabrata, maybe due to their ability to adapt to the urinary tract condition, as well as their intrinsic and/or acquired resistance to the conventional antifungals. Considering the high drug resistance of non albicans Candida species, especially C. glabrata, their dominance should be considered as a health concern and a probable cause of treatment failure. The assembly between candiduria and several demographic and laboratory data was assessed in the present investigation. Female gender, decreased (acidic) urine $\mathrm{pH}$, high FBS followed by glycosuria and uncontrolled diabetes (HbAlc $\geq 8$ ) were associated with candiduria. The antimicrobial susceptibility of Cinnamon extract shows the highest zone of inhibition against Candida tropicalis $(14.5 \mathrm{~mm})$ and the lowest zone of inhibition against Candida kefyr (10 mm). MIC values of Cinnamon extract on test organisms which the lowest concentration of Cinnamon extractable to inhibit the growth of Candida was $(0.187 \mathrm{~g} / 100 \mathrm{ml})$ appear against Candida krusseifollowed by Candida kefyr $(0.208 \mathrm{~g} / 100 \mathrm{ml})$, Candida tropicalis $(0.343 \mathrm{~g} / 100 \mathrm{ml})$, Candida albican $(0.375 \mathrm{~g} / 100 \mathrm{ml})$ and Candida glabrata $(0.458 \mathrm{~g} / 100 \mathrm{ml}$; susceptibility present is C. krussei (66.6\%), C. kefyr and C. tropicalis were $(100 \%)$. C. albican $(75 \%)$ and C. glabrata $(42.8 \%)$. According to NidhaiGoel et al the percent of anti-candida susceptibility of Cinnamon oil was $58.83 \%$ for $\mathrm{C}$. albicans, $46.51 \%$ for C. tropicalis, $44.45 \%$ for C. krussei and $57.12 \%$ for C. parapsilosis. The results of antimicrobial activity of the crude extract were compared with the positive control (Standard drugs) for evaluating their relative percentage inhibition while the aqueous extract exhibits maximum relative percentage inhibition against Candida kefyr $(89 \%)$ and minimum relative percentage inhibition against Candida glabrata $(12.3 \%)$ and it is statistically significant $(\mathrm{P}=0.018)$.

\section{CONCLUSION}

Considering the high incidence rate of candiduria in diabetic patients, diabetes, predisposing factors, and causal relationships between diabetes and candiduria. In addition, as the non-albicans Candida species were isolated more than C. albicans. Cinnamon extract can inhibit Candida species especially C. tropicalis.

\section{ACKNOWLEDGEMENT}

The authors appreciate an ethical review comm ittee of the selected health facilities and diabetic Patient $\mathrm{s}$ who consented to take part in the study and microbiol ogy team at the University of Shendi. 


\section{Funding}

The budget for this study was from personal co ntributions from the authors, with no external funding.

\section{REFERENCES}

1. Sewell, R. D., \& Rafieian-Kopaei, M. (2014). The history and ups and downs of herbal medicines usa ge. Journal of HerbMed pharmacology, 3 .

2. Andrade, S. S., Sader, H. S., Jones, R. N., Pereira, A. S., Pignatari, A. C., \& Gales, A. C. (2006). Incre ased resistance to first-line agents among bacterial pathogens isolated from urinary tract infections in Latin America: time for local guidelines?. Memória s do Instituto Oswaldo Cruz, 101(7), 741-748.

3. Brito, L. R., Guimarães, T., Nucci, M., Rosas, R. C ., Paula Almeida, L., Da Matta, D. A., \& Colombo, A. L. (2006). Clinical and microbiological aspects of candidemia due to Candida parapsilosis in Brazil ian tertiary care hospitals. Medical Mycology, 44(3) , 261-266.

4. Howes, D.S. (2009). Urinary Tract Infection, Fema le. http://emedicine. Medscape. Com / article/7786 70-print J eMedicine.

5. Cunha, B.A. (2009). Urinary Tract Infection, Males . http://emedicine.medscape.com/arti cle/ 2 31574overview J eMedicine. 2009.

6. Gruenwald, J., Freder, J., \& Armbruester, N. (2010 ). Cinnamon and Health Critical Reviews in Food S cience and Nutrition, 50; 822-834.

7. "Urinary Tract Infection". CDC. April 17, 2015. Ar chived from the original on 22 February 2016. Retr ieved 9 February 2016.

8. Study Guide for Pathophysiology (5 ed.). (2013). E 1sevier Health Sciences. 272. ISBN 978032329318 1. Archived from the original on 2016-02-16.

9. Colgan, R., Williams, M., Johnson, J.R (2011-09-0 1). "Diagnosis and treatment of acute pyelonephriti $\mathrm{s}$ in women". American Family Physician. 84 (5); 5 19-26.

10. Behzadi, P., Behzadi, E., Ranjbar, R. (2015). Urina ry tract infections and Candida albicans Cent Europ ean J Urol, 68; 96-101.

11. Manolakaki, D., Velmahos, G., Kourkoumpetis, T.,
Chang, Y., Alam, H. B., De Moya, M. M., Mylona kis, E. (2010). "Candida infection and colonization among trauma patients". Virulence, 1(5): 367-75. d oi:10.4161/viru.1.5.12796. PMID 21178472.

12. d'Enfert, C., Hube, B. (2007). Editors. Candida: co mparative and functional genomics. Norfolk: Caist er Academic Press.

13. Steckelberg, James, M. (2012-09-18). "Male yeast i nfection: Can I get it from my girlfriend?" Mayo $\mathrm{Cl}$ inic. Retrieved 2014-03-23.

14. Santos, M.A., Ueda, T., Watanabe, K., Tuite, M.F. (November 1997). "The non standard genetic code of Candida spp. An evolving genetic code or a nov el mechanism for adaptation?". Molecular Microbi ology, 26(3); 423-31.

15. Deutschlander, M. S. (2010). Isolation and identific ation of a novel anti-diabetic compound from Eucle a undulata Thunb (Doctoral dissertation, Universit y of Pretoria).

16. Cheesbrough, M. (2006). District laboratory practic e in tropical countries. $2^{\text {nd }}$ edition. Part 2.United Sta tes of America: Cambridge University Press.

17. Ahearn, D., Roth, F., Fell, J., Meyers, S. (1960). Us e of Shaken Cultures in the Assimilation Test for $\mathrm{Y}$ east Identification. J. Bacteriol, 79(3); 369-371.

18. Lin, C, Fung, D. (1987). Conventional and Rapid Methods for YeastIdentification. Critical Reviews i n Microbiology, 14(4), 273-289.

19. Pincus, D., Salkin, I., Hurd, N., Levy, I., Kemna, M . (1988). Modification of potassium nitrate assimila tion test for identification of clinically important ye asts. 1988. Journal of Clinical Microbiology, 26(2); 366-368.

20. Sukhdev. S. H., Suman. P. S. K., Gennaro, L., \& D ev. D.R. (2008). Extraction technologies for medici nal and aromatic plants. United Nation Industrial D evelopment Organization and the International Cen ter for Science and High Technology, 116.

21. Goel, N., Rohilla, H., Singh, G., \& Punia, P. (2016) . Antifungal activity of cinnamon oil and olive oil a gainst candida spp isolated from blood stream infec tions, journal of clinical and diagnostic research, A ug, Vol-10(8): DC09-DC11. 